\section{Crimen e historia en Estados Unidos: Scorsese : y el registro del mundo : criminal norteamericano} Crime and history in America: Scorsese
and the US criminal world Daniela Bobadilla ${ }^{1}$, Fernanda Pinto $^{2}$ :

\section{Resumen}

En el siguiente texto se explora cómo las vivencias personales del cineasta Martin Scorsese han tenido una fuerte influencia en sus cintas, por lo que ha registrado en ellas los cambios, variaciones y especificaciones del mundo criminal a lo largo de la historia de Estados Unidos. La vida ítaloamericana, los conceptos de culpa, mafias y violencia que vivió Scorsese en el contexto de su niñez, juventud y adultez entre los años cincuenta y ochenta del siglo pasado se reflejan en películas como "Gangs of New York" (Scorsese, 2002), "Goodfellas" (Scorsese, 1990), "Casino" (Scorsese, : 1995), "Mean Streets" (Scorsese, 1973) y "Taxi Driver" (Scorsese, 1976).

\begin{abstract} sese, 1973) and "Taxi Driver" (Scorsese, 1976).

\section{Palabras clave}

Martin Scorsese; Estados Unidos; gángsters; ciudad; crimen
\end{abstract}

The following text explores how personal experiences of filmmaker Martin Scorsese have had a strong influence on his films. He has printed the changes, variations and specifications of the criminal world throughout the history of United States. The Italian-American life, the concepts of guilt, mafia and violence that Scorsese lived during his childhood, youth and adulthood between 1950's and 1980's are reflected in films such as "Gangs of New York" (Scorsese, 2002), "Goodfellas" (Scorsese, 1990), "Casino" (Scorsese, 1995), "Mean Streets" (Scor-

\section{Key words}

Martin Scorsese; Unidos States of America; gangsters; city; crime

1. Universidad Peruana de Ciencias Aplicadas, Programa Académico de Comunicación Audiovisual y Medios Interactivos, e-mail: danielabobadilla23@hotmail.com

2. Universidad Peruana de Ciencias Aplicadas, Programa Académico de Comunicación y Publicidad, e-mail: mariafernandapinto2204@gmail.com

\section{SGRUPULOS}

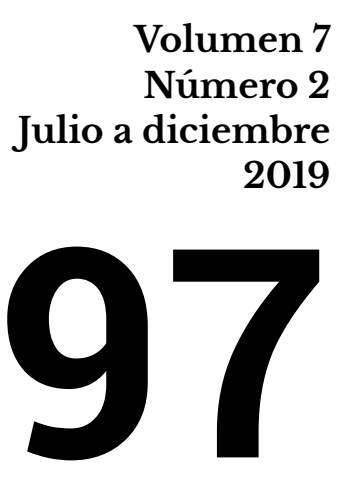

Citar como:

Bobadilla, D., Pinto, F.

(2019). Crimen e historia

en Estados Unidos:

Scorsese y el registro

del mundo criminal norteamericano.

CineScrúpulos, 7(2), 97 -

104.

DOI: https://doi.

org/10.19083/

cinescrupulos.v7i2.1265

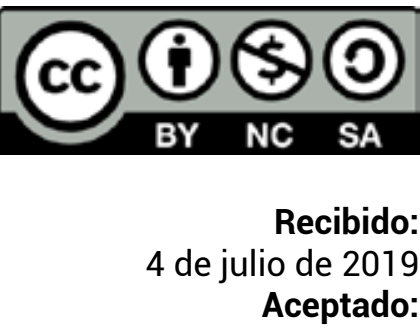

23 de setiembre de 2019

Publicado:

10 de diciembre de 2019 
scrupulos

Volumen 7

Número 2

Julio a diciembre 2019

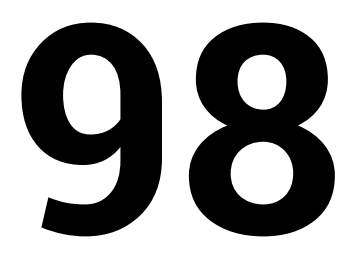

Existe una idea y un temor en la población de que puede pasar cualquier cosa en cualquier momento. Nueva York pasa de ser la ciudad que nunca duerme a ser la ciudad del miedo.
: Es preciso remontarnos al siglo XIX, cuando empezó todo. Nueva

: York era una ciudad con muchas guerras internas por los terri: torios pues se empezaron a formar poderosas mafias conforma: das principalmente por cinco familias. Estas eran bandas de in- migrantes italianos procedentes de pueblos pobres de Sicilia que : buscaban dinero y respeto a base de la fuerza. Estas dinastías no : tenían sucesiones de sangre (padre-hijo) pero realizaban acciones - sangrientas. Uno de los primeros crímenes que alarmó a la pobla: ción y a la prensa fue el caso del barril: un cadáver que se encontró : doblado en dos dentro de un tonel. Una frase célebre que expresa : muy bien el pensamiento de estas personas la encontramos en : "The Godfather" (Coppola, 1972): "Yo creo en América. América hizo mi fortuna". Es que los gángsters deseaban ser como los americanos o incluso mejores: más americanos que los americanos.

-

: Ya por los años setenta hay vandalismo, las calles están sucias y los

: cines pornográficos se ponen de moda. La mayoría de los metros lucen sucios y pintados con grafitis por fuera y por dentro y los : carteles advierten a los usuarios el cuidado de sus pertenencias. : Existe una idea y un temor en la población de que puede pasar cualquier cosa en cualquier momento. Nueva York pasa de ser la : ciudad que nunca duerme a ser la ciudad del miedo.

: En este contexto de violencia nace Martin Scorsese en 1942, en el : barrio de Queens. Tiene ascendencia italiana ya que sus padres y : sus abuelos fueron emigrantes sicilianos que se instalaron en Nue: va York en 1910. En 1950 Scorsese y su familia se mudan al barrio de sus abuelos en Little Italy, que fue en un principio judío y luego, : en el siglo XX, estuvo conformado por habitantes italianos. Creció : en un hogar de condición humilde: su padre era planchador y afi: cionado al cine mientras su madre se dedicaba al hogar y trabaja: ba como costurera. Little Italy podía ser un lugar poco adecuado y duro para un chico como Martin pues no era indiferente a las ma- fias ítaloamericanas. Este ambiente se refleja muy bien en "Mean : Streets" (Scorsese, 1973) y en "Goodfellas" (Scorsese, 1990), en las : cuales también encontramos un fuerte componente católico. Es : preciso mencionar que hubo un tiempo, aproximadamente en el : año 1956, en el que Scorsese quiso ser sacerdote; sin embargo, no - finalizó los estudios ya que, como él lo menciona, era la época del : rock and roll y le comenzaron a atraer las mujeres, distracciones : que imposibilitaron la culminación de sus estudios.

$\bullet$

$\bullet$

LA FUERZA DEL CONTEXTO

-

: Aproximadamente en los años cincuenta Scorsese se percata de - que muchas partes de su barrio son más antiguas que el resto. In: cluso descubre lápidas de 1810 en la Catedral de San Patricio o : sótanos debajo de grandes edificios que habían sido construidos : recientemente. Esto despertó en él una gran curiosidad acerca 
de la historia de la ciudad e, inspirado por el libro Gangs of New York de Herbert Asbury, decidió contar la historia de los inicios de Nueva York, cuando las inmigraciones eran el principal problema de aquella época.

En "Gangs of New York" (Scorsese, 2002) conocemos la historia de Amsterdam, un joven que busca vengar la muerte de su padre en : manos del líder de los nativos americanos, Bill "El carnicero", quien : envía al pequeño hijo de su rival a un reformatorio y no volvemos : a saber más de su historia hasta 16 años más adelante cuando el : joven Amsterdam sale del lugar en el que ha sido encerrado y se : percata que muchos de los partidarios del clan de los inmigrantes han olvidado a su padre. Por eso busca cobrar venganza y se gana la confianza de Bill, permitiéndole que asuma una figura paterna : mientras planea a escondidas cómo asesinarlo. Al ser descubierto, tras la traición de un amigo que expone los planes de Amsterdam, se gesta un enfrentamiento que despierta una rivalidad que había sido, de cierto modo, apaciguada entre ambos bandos.

Scorsese muestra una ciudad enfrentada por dos bandos que buscan dominar el territorio: los inmigrantes (italianos e irlandeses) y los nativos americanos. La película presenta la violencia y la venganza como protagonistas, tal como lo demuestran las crudas escenas de muertes masivas. Incluso desde el inicio vemos cómo ambos bandos se enfrentan sin importar la presencia de niños. Desde el inicio la historia es contada por un narrador que es el mismo protagonista. Nos muestra, además, una sociedad en la que existe una delgada línea entre la política y el mundo criminal y : que, en repetidas ocasiones, se desdibuja. Adicionalmente apre- : ciamos un factor importante en los personajes, quienes tienen ca- : rencias que los afectan de manera emocional e impulsan a actuar : con violencia. El personaje principal, Amsterdam, carece de una figura paterna en su vida, es un huérfano que busca protección y carece de un ambiente familiar pues observamos que su vínculo más cercano es con los demás miembros del clan.

Por otro lado, en "Goodfellas (Scorsese, 1990) Scorsese muestra : nuevamente una sociedad en la que la violencia no es ajena, pero : esta vez de la mano de los populares gángsters. Nos ubica en un tiempo más cercano al actual, aproximadamente en los años 1960. Cuenta la historia de Henry Hill, un niño que vive en una familia de clase media y que desde muy joven expresa sus deseos por: convertirse en gángster. Henry vive en East New York donde pre- : dominan personas ítaloamericanas, entre ellos la familia criminal Lucchese que sirve al joven de inspiración para aventurarse en : el mundo de la mafia. Es así como el protagonista abandona la escuela y a su corta edad gana más dinero que un adulto de clase acomodada. Claramente sus mayores no están de acuerdo con ello y su padre lo golpea cuando se entera que no asiste a la escuela; sin embargo, los mafiosos se encargan de resolver este proble- :

\section{SGRUPULOS}

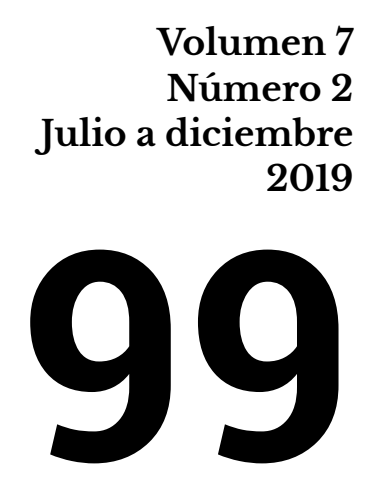

Scorsese muestra una ciudad enfrentada por dos bandos que buscan dominar el territorio: los inmigrantes (italianos e irlandeses) y los nativos americanos. La película presenta la violencia y la venganza como protagonistas, tal como lo demuestran las crudas escenas de muertes masivas. 

SGRUPULOS

Volumen 7

Número 2

Julio a diciembre 2019

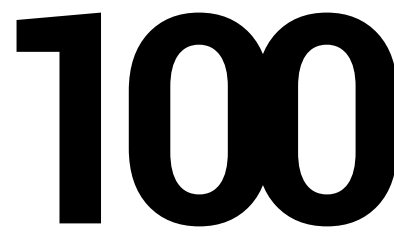

La película muestra cómo las mafias intentan justificar el por qué actúan de cierta manera, por qué esta violencia desmesurada es necesaria. Nos interna también en los pensamientos más profundos de estas personas que no quieren pasar desapercibidas ni ser "don nadies", que buscan respeto, lealtad, protección y reconocimiento.

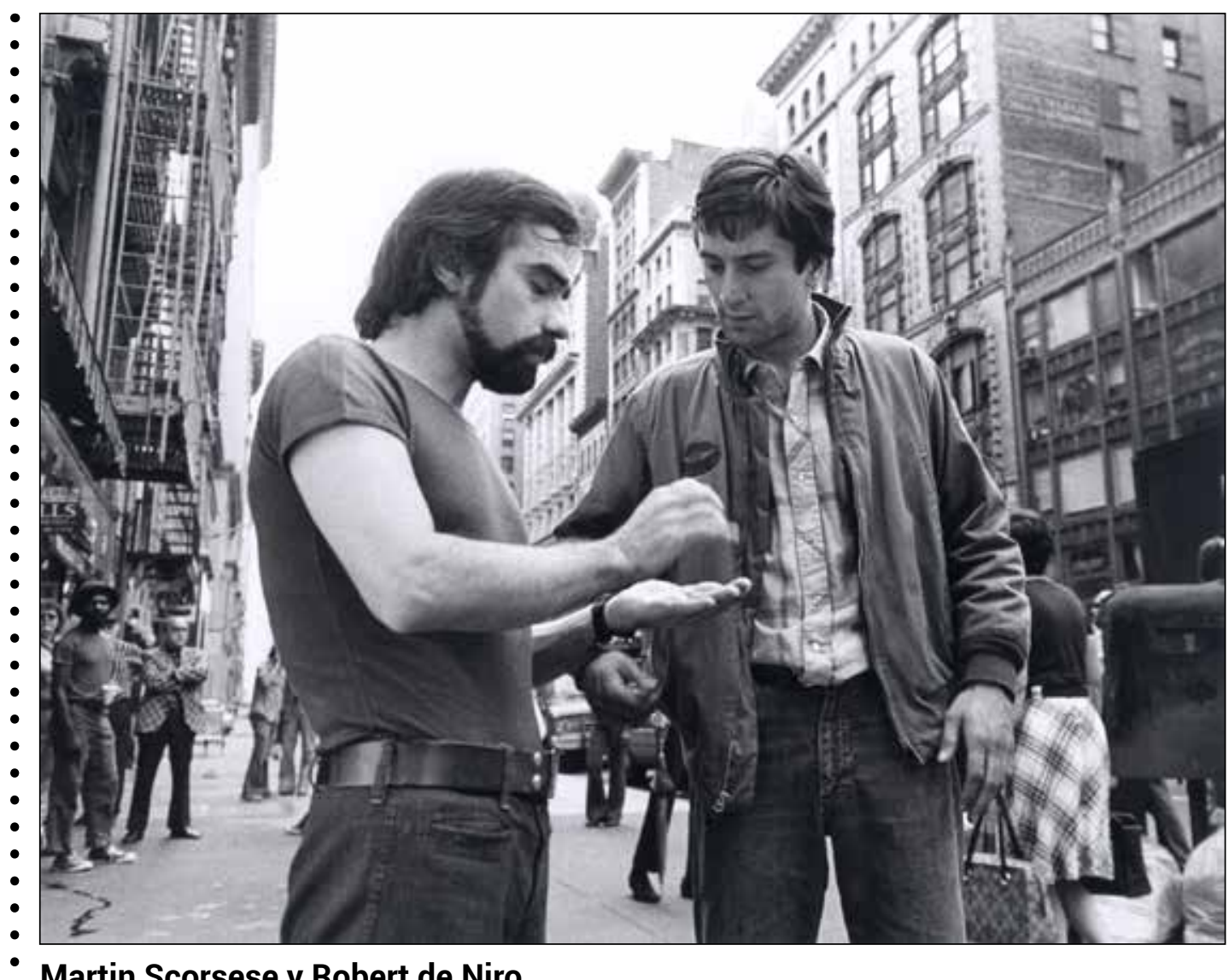

Martin Scorsese y Robert de Niro.

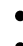

- ma amenazando al cartero que lleva a la casa de Henry los sobres : de la escuela. Adicionalmente aprende los grandes principios del - mundo de la mafia: "Nunca traiciones a un amigo y mantén siem- pre la boca cerrada". Poco a poco adquiere mayor confianza de los : líderes de esta agrupación y con el paso del tiempo se convierte en - un personaje importante en el negocio pero lleva una vida vacía, : deja sola a su esposa por meses y el dinero se vuelve algo funda- mental e indispensable. La misma vida que anhelaba lo lleva a la : violencia, el descontrol y los excesos hasta que lo deja finalmente : sin nada.

$\bullet$

: La película muestra cómo las mafias intentan justificar el por qué : actúan de cierta manera, por qué esta violencia desmesurada es : necesaria. Nos interna también en los pensamientos más profun: dos de estas personas que no quieren pasar desapercibidas ni ser - "don nadies", que buscan respeto, lealtad, protección y reconoci: miento y que la única manera de conseguir esto en un barrio que : cada vez se hunde en la miseria es unirse a las mafias. Estas perso: nas anhelan distinguirse de los otros "comunes y corrientes" que : se matan trabajando honestamente a cambio de un sueldo mísero - y ridículo. Son personas intocables pero actúan, irónicamente, de : una manera cobarde: se sienten valientes cuando están armados y 
se enfrentan a muchas otras personas, pero no tienen los valores o : las capacidades necesarias para enfrentarse al mundo.

\section{VISIONES DEL AYER}

"Mean Streets" (Scorsese, 1973) resalta la psicosis inducida por la soledad humana. Scorsese presenta en este film y en los mencionados anteriormente que sus personajes atraviesan profundas cri- : sis. Hombres y mujeres se ven atrapados en la ambición y están desolados. Son, en su mayoría, inmigrantes italianos que intentan, en medio de la delincuencia, la muerte y el catolicismo, sacar el lado positivo e intentar sobrevivir en América.

El cineasta nos demuestra cómo las costumbres, adversidades e influencias de la mafia italiana trascienden después de la Primera : Guerra Mundial y se posicionan en Nueva York. La película re- : construye sociológicamente a los ítaloamericanos y nos muestra sus costumbres, cómo se divierten, relacionan, aman, sueñan, odian y matan mientras buscan el gran sueño americano. "Mean Streets" (Scorsese, 1973) es una representación de Little Italy y de : las vivencias de Scorsese en ella. Cada personaje (Charlie, Michael, Tony, Teresa y el gran Johnny Boy) nos demuestra las esencias de muchachos y muchachas que viven la ambición del poder y del dinero, del arreglo de cuentas, del sexo y de los deseos. Scorsese se coloca a sí mismo y a sus amigos en la pantalla, muestra cómo : viven y cómo es la vida en Little Italy en escenas como la del billar: Charlie y Johnny caminan por las calles y patean unos tachos de basura, reflejan sus vivencias con amigos del barrio, los arreglos de cuenta, el sexo entre Charlie y su prima Teresa que representa lo prohibido, las cobranzas de Michael a Johnny que muestran : cómo las personas prestan dinero para comprar pistolas o cohetes. Si no se cancela la deuda, se paga con la muerte.

"Mean Streets" (Scorsese, 1973) es una película en la que el personaje de Charlie engloba el ambicioso álter ego de Scorsese. Por : eso al empezar la película el director habla mientras la pantalla se muestra en negro: "No se paga por los pecados en la iglesia. Se : paga en la calle". Con esto hace referencia a la redención: ya no basta con ir a la iglesia los domingos y cumplir con Dios, sino que se trata de cómo se vive, de con quién se relaciona uno. De esa manera se purga todo el mal que se comete. El catolicismo es parte de la película: observamos cantos en una iglesia y cómo Charlie quiere enmendar sus errores.

El film tiene también una particularidad respecto a la música ya : que aparecen canciones de rock and roll, ópera y baladas. Esta música envuelve las experiencias del director y lo ayudan a saber qué imágenes colocar ya que forman parte de su vida. Cada canción se conecta con lo que quiere expresar. Un claro ejemplo es cuando :

\section{SGRUPULOS}

Volumen 7

Número 2

Julio a diciembre

2019

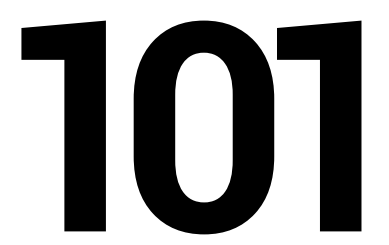

"Mean Streets"

(Scorsese, 1973) es una película en la que el personaje de Charlie engloba el ambicioso álter ego de Scorsese. Por eso al empezar la película

el director habla mientras la pantalla se muestra en negro:

"No se paga por los pecados en la iglesia. Se paga en la calle". 

SGRUPULOS

Volumen 7

Número 2

Julio a diciembre 2019

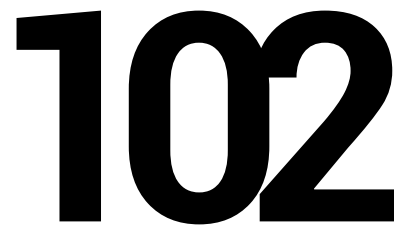

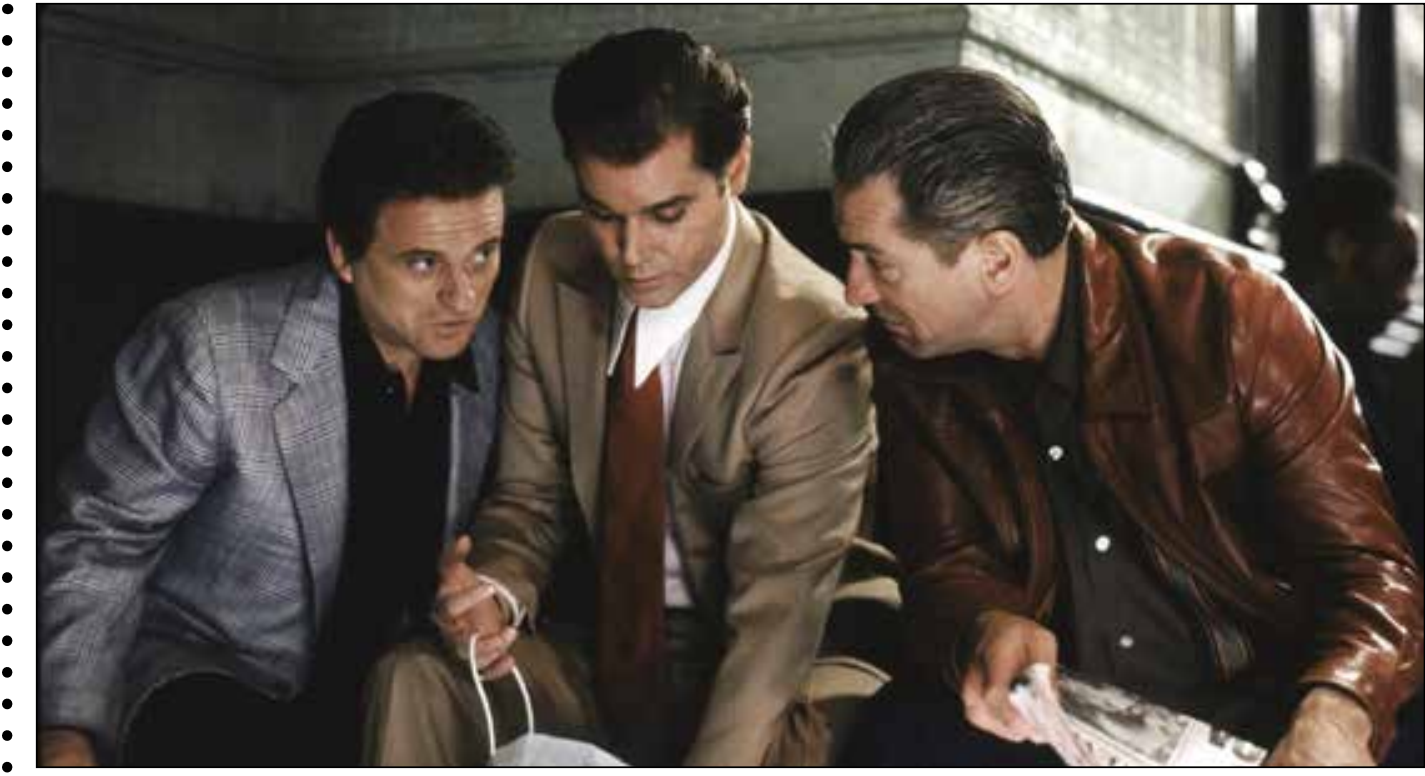

Goodfellas (Martin Scorsese, 1990). la cabeza de Harvey cae sobre la almohada y suena Be my baby o cuando la pelea en el billar se acompaña con Please, Mr. Postman.

Scorsese nos conecta con la película y con la vida de él mismo. : Charlie, el protagonista, representa al joven Martin que siempre - tiene presente en su cabeza el catolicismo. Por la fe que tiene y la - presencia de Dios en su vida quiere hacer el bien por la culpa y : la redención. Sin embargo, la mafia no lo hace vivir satisfecho y siempre busca el perdón de alguien.

\section{TRAVIS SE VAAL GASINO}

En "Taxi Driver" (Martin Scorsese, 1976) asistimos a la desilusión : de un hombre que vive con el síndrome de la soledad urbana.

- Travis Bickle es un personaje raro y solitario, un veterano de la guerra de Vietnam con desorden psicológico que necesita salvar : la sociedad porque cuando conduce su taxi de noche por Nueva - York encuentra delincuencia, prostitución, drogas y pandillas, a lo : que llama el virus de la humanidad. Lo dice en una frase: "Ojalá - una lluvia cayera sobre esta ciudad y limpiara toda esta escoria". : Scorsese muestra un individuo que busca el cambio en medio de : su soledad. representa al joven Martin que siempre tiene presente en su cabeza el catolicismo. $\bullet$

: Con este film, Scorsese hace referencia a las nuevas mafias que - aparecen: las mafias de personas y cómo los traficantes de mujeres : utilizan jovencitas para ganar dinero de forma ilegal. Travis co- 
noce a Iris, una niña de 12 años metida en el mundo de la prosti- : tución a quien busca liberar y salvar. Aunque todo finaliza en una : tragedia, la niña es libre. Es todo lo que quiere conseguir.

Si enlazamos la vida de Scorsese con el film, en "Taxi Driver" : (Scorsese, 1976) es posible identificar una anécdota que le cuen- : ta su padre sobre uno de sus tíos cuando paseaba por las calle de : regreso de la Segunda Guerra Mundial. Un coche liberó ligeras explosiones por el tubo de escape y el tío, por puro instinto, salió : corriendo. Travis está afectado por los recuerdos de la guerra de Vietnam: el insomnio, la carencia de comprensión del entorno, la : explosión posterior. Todas las situaciones terribles que observa en la vida nocturna debido a su nuevo trabajo no lo ayuda a superar sus problemas.

Scorsese crea un hilo empático con el personaje principal, nos hace vivir la realidad de sus problemas y de su nueva vida noctur- : na como taxista, así como el síndrome de soledad en el que está envuelto. El espectador se engancha y entiende que Travis quiere : hacer una depuración de toda la "infesta humana" que observa.

Finalmente, "Casino" (Scorsese, 1995) muestra la doble moral, la ambición y el camino de la destrucción. Sam se dedica a las apuestas y al juego de azar y es solicitado por la mafia para dirigir el ca- : sino Tangiers en Las Vegas. Ginger es una drogadicta y estafadora que le es infiel con Nicky, quien se encarga de proteger a Sam y : tiene un rango de capitán dentro del mundo de la mafia.

Scorsese muestra que dentro de la mafia existe una violencia ilíci- : ta entre personajes de diferentes bandos. "Casino" (Scorsese, 1995) cumple con el factor sorpresa. La musicalización es clave en el : film: Scorsese menciona que necesitaba música provocativa para referirse a los pecados y a la destrucción que se vive en conexión : con la expulsión de Lucifer del paraíso.

Scorsese muestra el arma de doble filo que implica involucrarse en : el mundo de la mafia. Por un lado está el dinero fácil, el sexo desenfrenado y un estilo de vida que no siempre será correcto. Pero la otra cara es la adicción, la traición, la venganza y la muerte. No hay punto : medio en la mafia: es un camino que lleva a la perdición.

\section{SGRUPULOS}

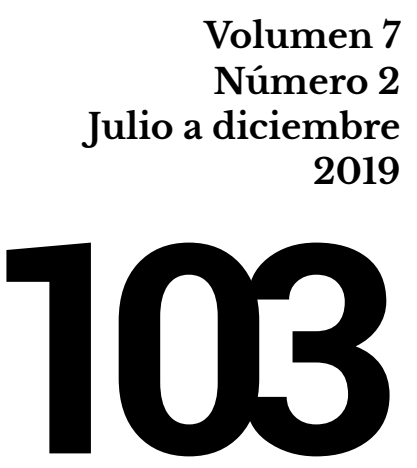

Scorsese muestra el arma de doble fillo que implica involucrarse en el mundo de la mafia. Por un lado está el dinero fácil, el sexo desenfrenado

y un estilo de vida que no siempre será correcto. Pero la otra cara es la adicción, la traición, la venganza y la muerte. 
ScRupuLOS

Volumen 7

Número 2

Julio a diciembre 2019

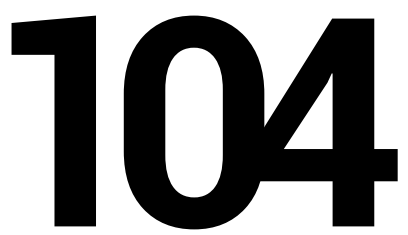

\section{: Referencias}

- El universo fílmico de Martin Scorsese, vasto y prolífico, presenta ánimos redentores pero es también la radiografía de una ciudad que se construyó a partir de la violencia.

Taplin, J. (Productor) y Scorsese, M. (Director). (1973). Mean Streets [Película]. Estados Unidos: Taplin - Perry Scorsese Productions.

Winkler, I. (Productor) y Scorsese, M. (Director). (1990). Goodfellas [Película]. Estados Unidos: Warner Bros.

Grimaldi, A., Weinstein, H. (Productores) y Scorsese, M. (Director). (2002). Gangs of New York [Película]. Estados Unidos e Italia: Initial Entertainment Group (IEG) y Alberto Grimal- di Productions.
amilinemera

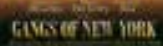

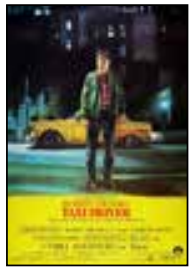

Phillips, J., Phillips, M. (Productores) y Scorsese, M. (Director). (1976). Taxi Driver [Película]. Estados Unidos: Bill/ Phillips e Italo/Judeo Productions.

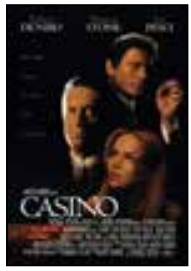

De Fina, B. (Productora) y Scorsese, M. (Director). (1995). Casino [Película]. Francia y Estados Unidos: De Fina-Cappa y GGG.
- Crimen e historia en Estados

- Unidos: Scorsese y el registro

- del mundo criminal

- norteamericano

- Referencia del artículo en APA:

- Bobadilla, D., Pinto, F. (2019).

- Crimen e historia en Estados

- Unidos: Scorsese y el registro del

- mundo criminal norteamericano.

- CineScrúpulos, 7(2), 97-104.
Crime and history in America: Scorsese and the US criminal world

Article reference in APA: Bobadilla, D., Pinto, F. (2019). Crime and history in America: Scorsese and the US criminal world. CineScrúpulos, 7(2), 97-104.

- Comunicaciones, Universidad Peruana de Ciencias Aplicadas. Este es un artículo de

- acceso abierto, distribuido bajo los términos de la LicenciaCreativeCommons Atribución-

- Compartirlgual 4.0 Internacional (http://creativecommons.org/licenses/by-sa/4.0/), que

- permite el uso no comercial, distribución y reproducción en cualquier medio, siempre que

- la obra original sea debidamente citada. 